\title{
Specific Plant Terpenoids and Lignoids Possess Potent Antiviral Activities against Severe Acute Respiratory Syndrome Coronavirus
}

\author{
Chih-Chun Wen, ${ }^{\dagger,}, \times$ Yueh-Hsiung Kuo, ${ }^{\S, \#, \times}$ Jia-Tsrong Jan, ${ }^{\nabla, \times}$ Po-Huang Liang, ${ }^{@}$ Sheng-Yang Wang, ${ }^{\prime \prime}$ Hong-Gi Liu, ${ }^{@}$ \\ Ching-Kuo Lee, ${ }^{\otimes}$ Shang-Tzen Chang, ${ }^{\perp}$ Chih-Jung Kuo, ${ }^{@}$ Shoei-Sheng Lee, ${ }^{\infty}$ Chia-Chung Hou, ${ }^{\dagger}$ Pei-Wen Hsiao, ${ }^{\dagger}$ \\ Shih-Chang Chien, ${ }^{\dagger}$ Lie-Fen Shyur, ${ }^{*} \dagger$ and Ning-Sun Yang*, ${ }^{*}$

\begin{abstract}
Agricultural Biotechnology Research Center, Academia Sinica, Taipei 115, Taiwan, R.O.C., Graduate Institute of Pharmaceutical Chemistry, Graduate Institute of Chinese Pharmaceutical Sciences, China Medical University, Taichung 404, Taiwan, R.O.C., Institute of Preventive Medicine, National Defense Medical Center, National Defense University, Taipei 114, Taiwan, R.O.C., Institute of Biological Chemistry, Academia Sinica, Taipei 115, Taiwan, R.O.C., Department of Forestry, National Chung-Hsing University, Taichung 402, Taiwan, R.O.C., Graduate Institute of Pharmacognosy Science, Taipei Medical University, Taipei 110, Taiwan, R.O.C., School of Forestry and Resource Conservation, National Taiwan University, Taipei 106, Taiwan, R.O.C., and School of Pharmacy, National Taiwan University, Taipei 105,
\end{abstract} \\ China Medical University, Taichung 404, Taiwan, R.O.C., Department of Chemistry, National Taiwan University, Taipei 106, Taiwan, R.O.C., \\ Taiwan, R.O.C.
}

Received March 14, 2007

In this study, 221 phytocompounds were evaluated for activity against anti-severe acute respiratory syndrome associated coronavirus (SARS-CoV) activities using a cell-based assay measuring SARS-CoV-induced cytopathogenic effect on Vero E6 cells. Ten diterpenoids (1-10), two sesquiterpenoids (11 and 12), two triterpenoids (13 and 14), five lignoids (15-19), curcumin (20), and reference controls niclosamide (21) and valinomycin (22) were potent inhibitors at concentrations between 3.3 and $10 \mu \mathrm{M}$. The concentrations of the 22 compounds to inhibit $50 \%$ of Vero E6 cell proliferation $\left(\mathrm{CC}_{50}\right)$ and viral replication $\left(\mathrm{EC}_{50}\right)$ were measured. The selective index values $\left(\mathrm{SI}=\mathrm{CC}_{50} / \mathrm{EC}_{50}\right)$ of the most potent compounds $\mathbf{1}, \mathbf{5}, \mathbf{6 , 8}, \mathbf{1 4}$, and 16 were 58, >510, 111, 193, 180, and >667, respectively. Betulinic acid (13) and savinin (16) were competitive inhibitors of SARS-CoV 3CL protease with $K_{\mathrm{i}}$ values $=8.2 \pm 0.7$ and $9.1 \pm 2.4 \mu \mathrm{M}$, respectively. Our findings suggest that specific abietane-type diterpenoids and lignoids exhibit strong anti-SARS-CoV effects.

\section{Introduction}

The worldwide outbreak of the life-threatening disease severe acute respiratory syndrome $\left(\mathrm{SARS}^{a}\right)$ was caused by infection with a novel coronavirus SARS-CoV. ${ }^{1-3}$ In 2003, this highly infectious disease was widely disseminated in 25 countries and resulted in 8098 probable SARS cases and 774 SARS-related deaths. At present, although a series of candidate drugs have been reported to ameliorate the disease, there are still no clinically approved or recommended antiviral drugs specific for SARS. Currently, the most frequently administered antiviral and supportive treatment of SARS is a combination of ribavirin and corticosteroids. ${ }^{4,5}$ Ribavirin, however, was only marginally effective against the SARS virus, and had serious adverse effects on SARS patients. ${ }^{6,7}$ The combination therapy of HIV protease

* Corresponding authors: Mailing address: No 128, Sec 2, Academia Road, Nankang, Taipei 115, Taiwan, R.O.C. Ning-Sun Yang: Tel: +8862-27851086 ext. 101, Fax: +886-2-26511127. E-mail: nsyang@ gate.sinica.edu.tw. Lie-Fen Shyur: Tel(Fax): +886-2-26515028. E-mail: lfshyur@ccvax.sinica.edu.tw.

Agricultural Biotechnology Research Center, Academia Sinica.

$\doteqdot$ Graduate Institute of Pharmaceutical Chemistry, China Medical University.

$\S$ National Taiwan University.

\# Graduate Institute of Chinese Pharmaceutical Sciences, China Medical University.

$\nabla$ National Defense University.

@ Institute of Biological Chemistry, Academia Sinica.

"National Chung-Hsing University.

$\otimes$ Taipei Medical University.

${ }^{\perp}$ School of Forestry and Resource Conservation, National Taiwan University.

${ }^{\infty}$ School of Pharmacy, National Taiwan University.

$\times$ Equal contribution to this article

a Abbreviations: SARS, severe acute respiratory syndrome; $\mathrm{CoV}$, coronavirus; $\mathrm{CPE}$, cytopathogenic effect. inhibitor drugs (lopinavir/ritonavir) plus ribavirin plus corticosteroids may improve some clinical outcomes, but only when administrated in the early phase of the illness. ${ }^{8,9}$ Since the emergence of SARS considerable effort has been put into antiviral research to screen and evaluate compounds for antiSARS-CoV activity in an attempt to prevent a re-emergence of the disease. Glycyrrhizin from licorice roots has been shown to inhibit SARS-CoV replication with a $50 \%$ effective concentration $\left(\mathrm{EC}_{50}\right)$ of $365 \mu \mathrm{M},{ }^{6}$ and a number of glycyrrhizin derivatives have been shown to possess modestly higher antiviral bioactivity. ${ }^{10,11}$ Calpain inhibitors, such as Val-Leu-CHO (calpain inhibitor VI) and Z-Val-Phe-Ala-CHO (calpain inhibitor III), have also been shown to be potent inhibitors of SARS-CoV replication. ${ }^{12}$

A number of protein molecules encoded by the SARS-CoV genome are potential targets for chemotherapeutic inhibition of viral infection, and replication. These intriguing targets include the spike protein $(\mathrm{S})$, which mediates the entry of the virus, the SARS-CoV main protease (3CL protease), the NTPase/helicase, the RNA-dependent RNA polymerase, the membrane protein (M) required for virus budding; the envelope protein (E) which plays a role in coronavirus assembly, ${ }^{13-18}$ and the nucleocapsid phosphoprotein $(\mathrm{N})$ that relates to viral RNA inside the virion and possibly other viral protein-mediated processes. ${ }^{19}$ With such a drastic increase in molecular and biochemical information about various components of the SARS-CoV and their cellular targets, it is important and timely to again evaluate anti-SARS$\mathrm{CoV}$ activities by different experimental approaches.

In the current study, we investigated the effects of specific phytocompounds on SARS virus using a Vero E6 cell-based cytopathogenic effect (CPE) assay. A total of 221 compounds 
with several specific chemical skeletons isolated from a number of medicinal plants were tested, of which a group of 22 compounds were chosen to have their anti-SARS-CoV bioactivities further characterized using ELISA. In parallel, these 22 compounds were also evaluated for inhibition of SARS-CoV $3 \mathrm{CL}$ protease activity. Structural modeling analysis was undertaken to interpret the intermolecular interactions in the compound-SARS-CoV 3CL protease complex. We demonstrate that some specific diterpenoids and lignoids have good potential as lead compounds for future development as anti-SARS therapeutics.

\section{Experimental Section}

Sources of Compounds Tested against SARS-CoV. More than 200 compounds were selected, tested and grouped based on their chemical structures and natural sources. Compounds 1 (ferruginol), 2 (dehydroabieta-7-one), 3 (sugiol), 5 [8 $\beta$-hydroxyabieta-9(11), 13dien-12-one)], 7 (6,7-dehydroroyleanone), $\mathbf{9}$ (pinusolidic acid), 12 ( $\alpha$-cadinol), 15 (hinokinin), and 16 (savinin) were purified from the ethyl acetate extracts of the heartwood of Chamaecyparis obtusa var. formosana. Compounds 8 (3/,12-diacetoxyabieta-6,8,11,13tetraene), 11 (cedrane-3 $\beta, 12$-diol), and 14 (betulonic acid) were isolated from the ethyl acetate extracts of the heartwood of Juniperus formosana. Compounds 4 (cryptojaponol) and 6 (7 $\beta$ hydroxydeoxycryptojaponol) were isolated from the heartwood of Cryptomeria japonica. Compound 17 (4,4'-O-benzoylisolariciresinol) is a synthetic liganoid. Compounds $\mathbf{1 0}$ (forskolin), $\mathbf{1 3}$ (betulinic acid), 20 (curcumin), 21 (niclosamide), and $\mathbf{2 2}$ (valinomycin) were purchased from Sigma-Aldrich (St. Louis, MO), and compounds 18 (honokiol) and 19 (magnolol) came from the Pharmaceutical Industry Technology Development Center in Taiwan. The remaining test compounds were laboratory chemical stocks stored as specialty compounds in the five participating research laboratories of this study.

Test compounds were first dissolved in $100 \%$ dimethyl sulfoxide (DMSO, Hybrix-Max, Sigma) and then transferred to 96-well microtiter plates for assay of activity against SARS-CoV-induced CPE, cytotoxicity in Vero E6 cells, inhibition of viral replication activity, and inhibition of 3CL protease activity. The final DMSO concentration in each assay was kept below $0.4 \%$.

Cell-Based Assay Utilizing CPE on Vero E6 Cells via SARSCoV Infection. For each compound treatment, eight wells were used for a complete set of assays, with three wells for virus-infection only (as positive control for CPE), three wells for virus-infection with compound treatment, and two wells with compound treatment only without viral infection. Briefly, Vero E6 cells $\left(2 \times 10^{4} /\right.$ well $)$ were cultured in 96-well plates in Dulbecco's modified Eagle's medium (DMEM) supplemented with $10 \%$ fetal bovine serum (FBS) at $37{ }^{\circ} \mathrm{C}$ in $5 \% \mathrm{CO}_{2}$ incubator for 1 day. Before cells in culture reached a $80-90 \%$ confluence, the cell culture medium was removed and replenished with $100 \mu \mathrm{L}$ of DMEM supplemented with $2 \%$ FBS. Test cell cultures at $\geq 90 \%$ confluence were treated with or without tested compounds in a DMEM + $2 \%$ FBS medium. After incubation for $2 \mathrm{~h}$ in a $5 \% \mathrm{CO}_{2}$ incubator at $37^{\circ} \mathrm{C}$, test cells were inoculated with SARS-CoV (Hong Kong strain) in $50 \mu \mathrm{L}$ at a dose of $100 \mathrm{TCID}_{50}$ (50\% tissue culture infectious doses) per well. The cytopathic morphology of cells was then observed and evaluated at $72 \mathrm{~h}$ postinfection by use of inverted phase contrast microscopy.

The inhibition by the tested compounds of SARS-CoV-mediated CPE was classified into three different levels $(+++,++,+)$ as previously reported by other laboratories. ${ }^{20}$ When less than $25 \%$ of Vero E6 cells in the culture showed cytopathogenic morphology in response to SARS-CoV after treatment with compound, the inhibition was scored as level +++ . The cultures showing $25-$ $50 \%$ and $50-70 \%$ cells as cytopathogenic are scored as level ++ and + , respectively.

Cytotoxic Effects of Test Compounds on Vero E6 Cells. Vero E6 cells $\left(2 \times 10^{4} /\right.$ well $)$ were grown in 96-well plates in DMEM supplemented with nonessential amino acids and 10\% FBS in a $5 \% \mathrm{CO}_{2}$ incubator at $37^{\circ} \mathrm{C}$. After 1 day of incubation where cells in culture reached $90 \%$ confluence, the culture medium was replaced by $100 \mu \mathrm{L}$ of fresh DMEM medium containing $2 \%$ FBS and test compounds at varying concentrations and placed into microwells and incubated for 3 days. The test culture medium was then replaced with $100 \mu \mathrm{L}$ of fresh culture medium containing 3-(4,5-dimethylthiozole-2-yl)-2,5-biphenyltetrazolium bromide (MTT) at a concentration of $0.5 \mathrm{mg} / \mathrm{mL}$ per well for $4 \mathrm{~h}$. Optical density (OD) was then measured with a spectrophotometer at $570 \mathrm{~nm}$. Survival of Vero E6 cells after treatment was calculated using the formula: viable cell number $(\%)=\left[\mathrm{OD}_{570}(\right.$ treated cells) $\left.)\right] / \mathrm{OD}_{570}($ vehicle control cells $\left.)\right]$ $\times 100 . \mathrm{CC}_{50}$ represented the level at which $50 \%$ of cell viability was reduced by $50 \%$.

Inhibition of Viral Replication in SARS-CoV-Infected Vero E6 Cells. After the Vero E6 cells with test compounds added had been incubated for 3 days with SARS-CoV, the cells were gently rinsed with PBS three times and then fixed with $10 \%$ formalin for $5 \mathrm{~min}$ at room temperature. The $10 \%$ formalin was removed and the cells fixed again in methanol/acetone (v/v, 1:1) solution for 5 min at room temperature. Cells were then blocked with $3 \%$ skim milk in PBS for $2 \mathrm{~h}$ at room temperature, rinsed three times with PBS, and then incubated for $1 \mathrm{~h}$ at $37^{\circ} \mathrm{C}$ with 1:2000 dilution of monoclonal antibody against the spike protein of SARS-CoV. All samples were then rinsed with three changes of PBS containing $0.05 \%$ Tween 20 (PBS-T buffer), twice with fresh PBS at room temperature, and finally with $3 \%$ skim milk in PBS-T buffer. Cells were then incubated with a horseradish peroxidase-conjugated goat anti-mouse IgG for $30 \mathrm{~min}$ at room temperature. After the cells were rinsed three times with PBS-T buffer, a substrate solution containing $O$-phenylenediamine dihydrochloride, citrate buffer $(\mathrm{pH}$ 5.0 ), and hydrogen peroxide was added to each well. Plates were covered and gently shaken at room temperature for $10 \mathrm{~min}$ in the dark. The reaction was stopped by addition of $2 \mathrm{~N}$ sulfuric acid, and plate absorbance was read immediately at $492 \mathrm{~nm}$ with an ELISA reader. The $\mathrm{EC}_{50}$ value for each test compound was calculated from a linear regression plot of compound concentration versus $\mathrm{OD}_{492}$.

SARS-CoV 3CL Protease Inhibition Assay. As previously reported, ${ }^{21,22}$ the gene encoding the SARS-CoV main protease was cloned from the whole viral genome by polymerase chain reaction (PCR) and primer insertion (forward primer 5'-GGTATTGAGGGTCGCAGTGGTTTTAGG-3' and reverse primer 5'-AGAGGAGAGTTAGAGCCTTATTGGAAGGTAACACC-3') into the $\mathrm{pET} 32 \mathrm{Xa} / \mathrm{Lic}$ vector. The recombinant $3 \mathrm{CL}$ protease plasmid was then transformed into E. coli JM109 competent cells that were streaked on a Luria-Bertani (LB) agar plate containing $100 \mu \mathrm{g} / \mathrm{mL}$ ampicillin. The correct construct was subsequently transformed into E. coli BL21 host cells for expression of the His-tagged protein, which was then digested with FXa protease to remove the tag. The purified protein was confirmed by $\mathrm{N}$-terminal sequencing and mass spectrometry analysis. The enzyme concentration used in all experiments was determined from the absorbance at $280 \mathrm{~nm}$.

All kinetic measurements were performed in a solution containing $20 \mathrm{mM}$ bis[(2-hydroxyethyl)amino]tris(hydroxymethyl)methane ( $\mathrm{pH}$ $7.0)$ at $25{ }^{\circ} \mathrm{C}$. Enhanced fluorescence due to cleavage of the fluorogenic substrate peptide (Dabcyl-KTSAVLQ-SGFRKMEEdans) of SARS 3CL-protease was monitored at $538 \mathrm{~nm}$ with excitation at $355 \mathrm{~nm}$ on a fluorescence plate reader. The initial velocities of the inhibiting activities on $50 \mathrm{nM}$ SARS 3CL-protease using $6 \mu \mathrm{M}$ fluorogenic substrate were plotted against the different inhibitor concentrations to obtain the $\mathrm{IC}_{50}$ values using eq 1 :

$$
A_{[I]}=A_{[0]} \times\left\{1-\left[[\mathrm{I}] /\left([\mathrm{I}]+\mathrm{IC}_{50}\right)\right]\right\}
$$

where $A_{[\mathrm{I}]}$ is the enzyme activity with inhibitor concentration [I]; $A_{[0]}$ is the enzyme activity without interference from an inhibitor. $K_{\mathrm{i}}$ measurements were performed at two fixed inhibitor concentrations and various substrate concentrations ranging from 8 to 80 $\mu \mathrm{M}$ in a reaction mixture containing $50 \mathrm{nM}$ SARS protease. Lineweaver-Burk plots of kinetic data were fitted using the 


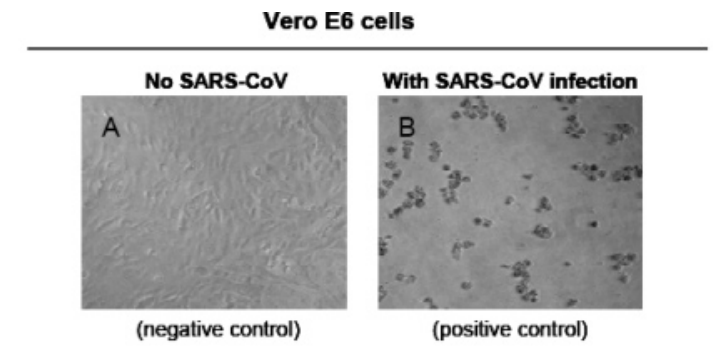

Vero E6 cells + SARS-CoV (100 TCID $_{50} /$ well) + test Compounds

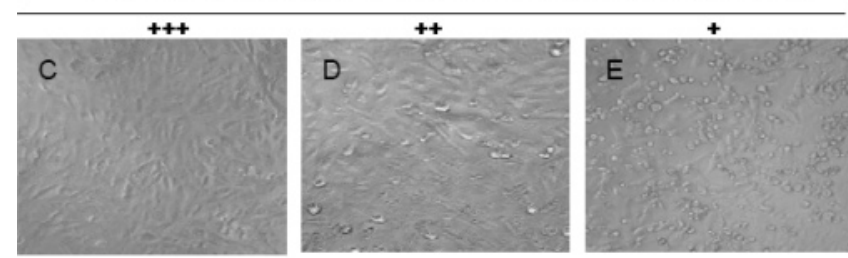

The protective effect of test compounds

Figure 1. Characterization of compound inhibition of the cytopathogenic effect (CPE) of SARS-CoV on Vero E6 cells using a cell-based assay. (A and B) Represent cell culture phenotypes or behavior of Vero E6 cells with or without infection with SARS-CoV. C, D, and E represent semiquantitatively the three levels (high +++ , moderate ++ , and low + , respectively) of CPE inhibition, as evaluated by phase contrast microscopy.

computer program KINETASYST II (IntelliKinetics, State College, PA) by nonlinear regression to obtain the $K_{\mathrm{i}}$ value for competitive inhibition from eq 2 :

$$
1 / V=K_{\mathrm{m}} / V_{\mathrm{m}}\left(1+[I] / K_{\mathrm{i}}\right) 1 /[S]+1 / V_{\mathrm{m}}
$$

where $K_{\mathrm{m}}$ is the Michaelis constant of the substrate, $K_{\mathrm{i}}$ is the inhibition constant, $V_{\mathrm{m}}$ is maximal velocity, and [I] and [S] represent the inhibitor and substrate concentrations in the reaction mixture, respectively.

Computer Modeling of SARS-CoV 3CL Protease Inhibition. Molecular docking was performed with the computer program Discovery Studio Modeling 1.2 SBD, (Accelrys, Inc., San Diego, CA). The core domain in subunit A of the X-ray structure of the SARS-CoV 3CL protease in complex with a substrate-analogue inhibitor (coded 1uk4) ${ }^{23}$ obtained from the Protein Data Bank (PDB; http://www.rcsb.org/pdb/) was used for modeling analysis. Docking experiments were performed using an automated ligand-docking subprogram of the computer program (Discovery Studio Modeling 1.2 SBD) that uses a genetic algorithm to fit ligands into the active site of the SARS protease in 3-D mode. A number of parameters were chosen to control the precise operation of the genetic algorithm via defined binding sites, specified ligand conformations, energy grid parameter, variable numbers of Monte Carlo trials, and selected score type. Docking runs were carried out using standard default settings ("grid resolute" of $5 \AA$, "site opening" of $12 \AA$, "binding site" selected) of the active site cavity which are similar to those used when fitting the inhibitors in a previous report. ${ }^{24}$ The interaction energy was calculated from Dreiding/Gasteiger forcefield, and poses with DockScore below 0 were rejected. 1000 iterations were performed in the "in situ ligand minimization algorithm" of the Smart Minimization program.

\section{Results}

Anti-SARS-CoV Activity Detected by Cell-Based CPE Assay. A cell-based assay of cytopathogenic effect on Vero E6 cells infected with SARS virus was adopted to investigate the anti-SARS-CoV activity of 221 selected phytocompounds. Figure 1, panel A, shows the original morphology of the Vero E6 cells without treatment (negative control), and panel B shows the cytopathic morphology of Vero E6 cells after infection with
SARS viruses (positive control). The inhibition of CPE of SARS virus on Vero E6 cells was expressed as levels,+++++ , and + (where +++ represented the most inhibition and + represented the least inhibition) as shown in panels C, D, and E, respectively, in Figure 1. Glycyrrhizin and $18 \beta$-glycyrrhetinic acid, previously reported to have anti-SARS bioactivity, were employed in this study as reference control samples. ${ }^{6,11}$ Among the tested compounds, 22 compounds with structures depicted in Chart 1, comprising terpenoids (compounds $\mathbf{1 - 8}$ as abietanetype diterpenes, compounds $\mathbf{9}$ and $\mathbf{1 0}$ as labdane-type diterpenes, compounds 11 and 12 as sesquiterpenes, and compounds 13 and 14 as triterpenes), lignoids (compounds 15-19), curcumin (20), niclosamide (21), and valinomycin (22), showed high inhibition (level ++ or +++ ) activity in the CPE assays at concentrations between 3.3 and $20 \mu \mathrm{M}$ (Table 1). Moreover, compounds 12, 15, 21, and 22 also exhibited significant inhibitory effects at concentrations as low as $1 \mu \mathrm{M}$. Interestingly, glycyrrhizin and $18 \beta$-glycyrrhetinic acid were found to exhibit little or no activity in CPE reduction at a concentration of 20 $\mu \mathrm{M}$. To evaluate whether the used vehicle solvent $(0.2-0.4 \%$ DMSO) in this report would cause any possible cytotoxic or negative effect on test Vero E6 cells, MTT assay and microscopic examination were performed. Our result showed that little or no cytotoxic effect was observed in $0.2-0.4 \%$ DMSO-treated cells, as 93 to $96 \%$ cells were viable (data not shown); in addition, there was no morphological changes of test cells observed in the same tested DMSO concentrations.

Inhibition of SARS-CoV Replication Evaluated Using ELISA. To investigate whether the 22 compounds that exhibited potent inhibitory activity on the cytopathogenic effect of SARS$\mathrm{CoV}$ could also inhibit viral replication, levels of spike protein in SARS-CoV-infected Vero E6 cells, with or without treatment with test compounds, were measured by ELISA. As examples, the anti-SARS-CoV replication activity of four selected compounds at indicated concentrations $(0.1-10 \mu \mathrm{M})$ are shown in Figure 2A. The concentration which was able to inhibit $50 \%$ of viral replication $\left(\mathrm{EC}_{50}\right)$ was calculated and summarized in Table 2. In contrast to compounds 4, 11, 13, 15, and 20 which had $\mathrm{EC}_{50}$ values higher than $10 \mu \mathrm{M}$, the $\mathrm{EC}_{50}$ values of the four abietane-type diterpenes $(\mathbf{1}, \mathbf{5}, \mathbf{6}$, and $\mathbf{8})$, one triterpene (14), one lignan (16), and niclosamide (21) were determined to be $1.39,1.47,1.15,1.57,0.63,1.13$, and $<0.1 \mu \mathrm{M}$, respectively. These values are similar to or even lower than that of the reference compound valinomycin $(\mathbf{2 2})\left(\mathrm{EC}_{50}=1.63 \mu \mathrm{M}\right)$. A number of other tested compounds $(2,7,9,10,12,18$, and 19) also showed appreciable levels of anti-SARS virus bioactivity with $\mathrm{EC}_{50}$ values ranging from 3.8 to $7.5 \mu \mathrm{M}$.

Cytotoxic Effects of Test Compounds on Vero E6 Cells. Since the anti-SARS-CoV activity observed with the use of the test compounds might have resulted from a direct inhibition on the growth of test cells, MTT assay was employed to evaluate the cytotoxic effect of test compounds at concentrations ranging from 20 to $750 \mu \mathrm{M}$ on Vero E6 cells. The experiment was performed with test compounds prepared in DMEM supplemented with $2 \%$ FBS. Figure $2 \mathrm{~B}$ shows the results for compounds $\mathbf{1}, \mathbf{5}, \mathbf{8}$, and $\mathbf{1 4}$ as examples of this study. The cytotoxic concentration of individual compounds that reduced the cell viability to $50 \%$ of the untreated control $\left(\mathrm{CC}_{50}\right)$ was calculated. The $\mathrm{CC}_{50}$ values (summarized in Table 2) for most of the test compounds $(1,4,7,12,13,14,18$, and 19), except 21 (niclosamide, $\mathrm{CC}_{50}=22.1 \mu \mathrm{M}$ ), were $>65 \mu \mathrm{M}$, indicating that these compounds might interfere only slightly with the growth of Vero E6 cells. In addition, compounds 2, 5, 8, 9, 10, 11, 15, 16, and 20 had a $\mathrm{CC}_{50}$ of $>250 \mu \mathrm{M}$; these chemicals 
Chart 1. Chemical Structures of the 22 Compounds That Exhibit Significant Inhibitory Activity against the Cytopathogenic Effect of SARS-CoV on Vero E6 Cells

\section{A Terpenoids}<smiles>CC(C)c1cc2c(cc1O)C1(C)CCCC(C)(C)C1CC2</smiles>

1<smiles>[R]c1c(C(C)C)cc2c(c1[R])C1(C)CCCC(C)(C)C1CC2=O</smiles>

$2 \mathrm{R}_{1}=\mathrm{H} \quad \mathrm{R}_{2}=\mathrm{H}$

$3 \mathbf{R}_{1}=\mathrm{H} \quad \mathbf{R}_{2}=\mathrm{OH}$

$4 R_{1}=O H \quad R_{2}=O C_{3}$<smiles>CC(C)C1=CC2(O)CCC3C(C)(C)CCCC3(C)C2=CC1=O</smiles>

5<smiles>COc1c(C(C)C)cc2c(c1O)C1(C)CCCC(C)(C)C1CC2O</smiles>

6<smiles>CC(C)C1=C(O)C(=O)C2=C(C=CC3C(C)(C)CCCC23C)C1=O</smiles>

7<smiles>CC(=O)OC1CCC2(C)C(C)=CC3CCCCCCCCC3C2C1(C)C(C)(C)C(=O)O</smiles>

8

9<smiles>C=CC1(C)CC(=O)C2(C)C(C)(O1)C(OC(C)=O)C(O)C1C(C)(C)CCC(O)C12O</smiles>

10

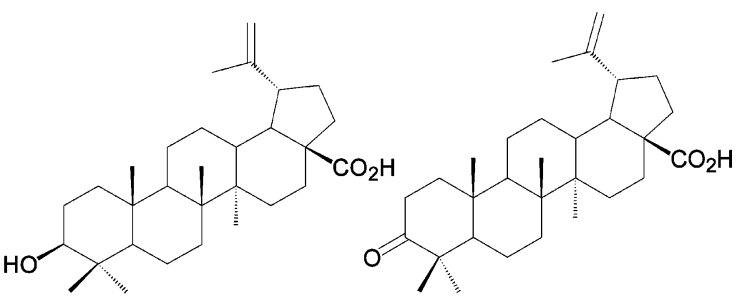

11

12

13

14

\section{B Lignoids}<smiles>O=C1OCC(Cc2ccc3c(c2)OCO3)C1Cc1ccc2c(c1)OCO2</smiles>

15<smiles>O=C1OCC(Cc2ccc3c(c2)OCO3)/C1=C/c1ccc2c(c1)OCO2</smiles>

16<smiles>COc1cc(C2c3cc(OC(=O)c4ccccc4)c(OC)cc3C[C@H](CO)C2CO)ccc1OC(=O)c1ccccc1</smiles>

17<smiles>[R2]c1cc([R2])c(-c2cc(CC=C)ccc2O)cc1CC=C</smiles>

$18 \mathrm{R}_{1}=\mathrm{H} \quad \mathrm{R}_{2}=\mathrm{OH}$ $19 R_{1}=O H \quad R_{2}=H$

\section{Miscellaneous}

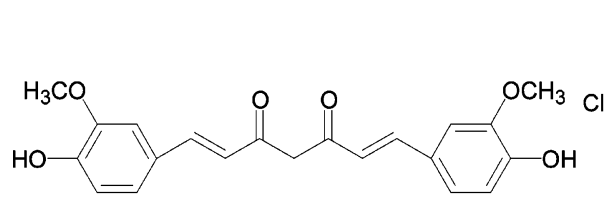

20

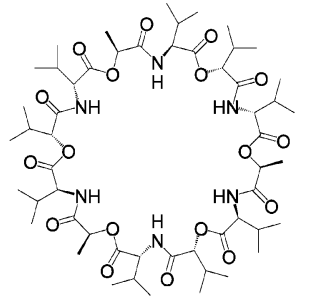

22

(A) Terpenoids. The fourteen terpenoids were ten diterpenes, including eight abietane derivatives (1-8) and two labdane derivatives $(\mathbf{9}, \mathbf{1 0})$, two sesquiterpenes $(\mathbf{1 1}, \mathbf{1 2})$, and two triterpenes $(\mathbf{1 3}, \mathbf{1 4})$. (B) Lignoids. The five lignoids were three lignan derivatives $(\mathbf{1 5}-\mathbf{1 7})$ and two neolignans $(\mathbf{1 8}, \mathbf{1 9})$. (C) Miscellaneous. This group includes one phenolic compound (20, curcumin) and two known anti-SARS-CoV compounds used as positive controls (21, 22). Individual compounds: 1: ferruginol, 2: dehydroabieta-7-one, 3: sugiol, 4: cryptojaponol, 5: [8 $\beta$-hydroxyabieta-9(11),13-dien-12-one)], 6: 7 $\beta$-hydroxydeoxycryptojaponol, 7: 6,7-dehydroroyleanone, 8: 3 $\beta, 12$-diacetoxyabieta-6,8,11,13-tetraene, 9: pinusolidic acid, 10: forskolin, 11: cedrane-3 $\beta, 12$-diol, 12: $\alpha$-cadinol, 13: betulinic acid, 14: betulonic acid, 15: hinokinin, 16: savinin, 17: 4,4'-O-benzoylisolariciresinol, 18: honokiol, 19: magnolol, 20: curcumin, 21: niclosamide, and 22: valinomycin.

can thus be considered as biologically safe to host cells. On the basis of the results in Table 2, we suggest that it is quite unlikely that the observed inhibitory effects of compounds 1-22 on viral replication of SARS-CoV were due to the inhibitory effect on growth of host cells. The selective index (SI), the ratio of $\mathrm{CC}_{50}$ to $\mathrm{EC}_{50}$, was also calculated to demonstrate the potency of anti-SARS-CoV activity of test compounds (Table 2). The SI of the five abietane-type diterpenes $(\mathbf{1}, \mathbf{2}, \mathbf{5}, \mathbf{6}$, and 8), two labdane-type diterpenes (9 and 10), one triterpene (14) and one lignan (16) were determined to be 58, 76.3, > 510, 111, 193, $>159,89.8,180$, and $>667$, respectively. These SI values are all much higher than the value of the reference control 
Table 1. Phytocompounds Tested against CPE of SARS-CoV on Vero E6 Cells ${ }^{a}$

\begin{tabular}{|c|c|c|c|c|c|}
\hline \multirow[b]{2}{*}{ compound } & \multicolumn{5}{|c|}{ test concentration $(\mu \mathrm{M})$} \\
\hline & 20 & 10 & 3.3 & 1 & 0 \\
\hline \multicolumn{6}{|c|}{ Diterpenoids (Abietane-type) } \\
\hline 1 & +++ & +++ & ++ & - & - \\
\hline 2 & +++ & +++ & N.T. & N.T. & - \\
\hline 3 & +++ & +++ & N.T. & N.T. & - \\
\hline 4 & +++ & +++ & N.T. & N.T. & - \\
\hline 5 & +++ & +++ & + & - & - \\
\hline 6 & +++ & +++ & N.T. & N.T. & - \\
\hline 7 & +++ & ++ & - & - & - \\
\hline 8 & +++ & ++ & ++ & - & - \\
\hline \multicolumn{6}{|c|}{ Diterpenoids (Labdane-type) } \\
\hline 9 & +++ & +++ & N.T. & N.T. & - \\
\hline 10 & +++ & ++ & + & - & - \\
\hline \multicolumn{6}{|c|}{ Sesquiterpenoids } \\
\hline 11 & +++ & ++ & + & - & - \\
\hline 12 & +++ & ++ & ++ & + & - \\
\hline \multicolumn{6}{|c|}{ Triterpenoids (Lupane-type) } \\
\hline 13 & +++ & ++ & + & - & - \\
\hline 14 & +++ & +++ & N.T. & N.T. & - \\
\hline \multicolumn{6}{|c|}{ Lignoids } \\
\hline 15 & +++ & ++ & ++ & + & - \\
\hline 16 & +++ & +++ & N.T. & N.T. & - \\
\hline 17 & +++ & +++ & N.T. & N.T. & - \\
\hline 18 & +++ & +++ & ++ & - & - \\
\hline 19 & +++ & +++ & + & - & - \\
\hline curcumin, 20 & ++ & + & - & - & - \\
\hline niclosamide, 21 & +++ & ++ & ++ & + & - \\
\hline valinomycin, 22 & +++ & ++ & ++ & + & - \\
\hline glycyrrhizin, GL & - & - & - & - & - \\
\hline $18 \beta$-glycyrrhetinic acid & - & - & - & - & - \\
\hline
\end{tabular}

valinomycin $(\mathrm{SI}=41.4)$, determined in parallel in this study and previously reported. ${ }^{10}$

Inhibition of SARS-CoV 3CL Protease Activity. The proteolytic cleavage of polyprotein at specific sites by $3 \mathrm{CL}$ protease is essential for the replication of SARS-CoV. ${ }^{21,23}$ For a better understanding of possible sites on the virus targeted by the specific anti-SARS compounds, all 22 compounds were evaluated in a $3 \mathrm{CL}$ protease inhibition assay. $\mathrm{IC}_{50}$ values of compounds were measured by a quenched fluorescence energy transfer (FRET) method. ${ }^{21}$ None of the diterpenoids tested inhibited SARS-CoV 3CL protease at concentrations of less than $100 \mu \mathrm{M}$. Betulinic acid (13), savinin (16), curcumin (20), and niclosamide (21) showed inhibitory effects on 3CL protease activity with $\mathrm{IC}_{50}$ values of $10,25,40$, and $40 \mu \mathrm{M}$, respectively. In contrast, betulonic acid (14) and hinokinin (15), analogues of compounds 13 and 16, respectively, inhibited 3CL-protease activity with $\mathrm{IC}_{50}$ values $>100 \mu \mathrm{M}$ (Table 3 ). We then further characterized the inhibitory mechanism of the two most potent compounds, 13 and 16, against SARS-CoV 3CL protease activity. The $K_{\mathrm{i}}$ values of betulinic acid (13) and savinin (16) were determined at $8.2 \pm 0.7$ and $9.1 \pm 2.4 \mu \mathrm{M}$, with a competitive inhibition mode of action (Figure 3).

Structural Modeling of Compounds 13-15 with SARSCoV 3CL Protease. Structural modeling was employed to examine the differential inhibition of SARS-CoV 3CL protease by compound analogues. A previous X-ray diffraction study showed that SARS-CoV 3CL protease has a Cys-His catalytic dyad (Cys145 and His41) located and formed between the domain I (residues 8-101) and domain II (residues 102-184) of the $3 \mathrm{CL}$ protease. ${ }^{22}$ Computer docking analysis revealed that betulinic acid (13) can be nicely fitted into the substrate-binding pocket of SARS-CoV 3CL protease. In addition, the hydroxyl group of $\mathrm{C} 3$ of $\mathbf{1 3}$ formed a hydrogen bond with the oxygen atom of the carbonyl group of Thr24 located at the N-terminus of domain I (residues 8-101) of the 3CL protease to strengthen the binding. In contrast, betulonic acid (14) did not form additional intermolecular bonds with the enzyme besides the hydrophobic interaction (Figure 4A). For hinokinin (15) and savinin (16), the computer modeling analyses (Figure 4B) suggested that savinin fits into the active site cavity better by forming hydrogen bonds with the NHs of Gly143, Ser144, and Cys145 via the $\mathrm{O}$ atoms located at $\mathrm{C} 9$, and with the $\mathrm{NHs}$ of Glu166 and Gln189 via oxygen atoms attached to C3' and C4', respectively. However, hinokinin only forms a $\mathrm{H}$-bond between the $\mathrm{O}$ atom located at $\mathrm{C} 9$ and the $\mathrm{NH}$ of Ser144. Moreover, only the C4' $\mathrm{O}$ atom on hinokinin forms a H-bond with Gln189. These differences of intermolecular interaction apparently are reflected by the 4-fold smaller $K_{\mathrm{i}}$ value of savinin compared with that of hinokinin in inhibiting the $3 \mathrm{CL}$ protease (Table 3 ). In fact, the only difference in the chemical structures of hinokinin and savinin is the single vs double bond between $\mathrm{C} 7$ and $\mathrm{C} 8$. The more rigid structure from the double bond found in savinin (forming a planar structure in the C7, C8 and the lactone ring) ensures its proper binding with the 3CL protease.

\section{Discussion}

Despite intense research efforts since its sudden appearance in 2003 , there is as yet no laboratory proven or clinically defined treatment for the significant public health risk posed by severe acute respiratory syndrome (SARS). For adequate public safety and control of infection in the event of a re-emergence of the disease, the identification of effective anti-SARS-CoV agents is essential. In this study, we employed a cell-based cytopathogenic effect (CPE) assay of the SARS virus in Vero E6 cells, to screen more than 200 phytocompounds for potential antiSARS-CoV activity. Twenty tested phytocompounds exhibited significant levels ( ++ to +++ ) of anti-SARS-CoV activity at $10 \mu \mathrm{M}$, and these unique features of test compounds have not been previously reported (Table 1). The newly identified bioactive compounds with anti-SARS-CoV activity in the $\mu \mathrm{M}$ range include abietane-type $(\mathbf{1}-\mathbf{8})$ and labdane-type diterpenes (9 and 10), sesquiterpenes (11 and 12), lupane-type triterpenes (13 and 14), lignoids (15-19), and curcumin (20). Although $\alpha$-cadinol (12) has previously been shown to exhibit strong antifungal, ${ }^{25}$ antitermitic, ${ }^{25,26}$ and antitumoral ${ }^{27}$ activities, this is the first time it has been shown to possess antiviral activity.

Because CPE of viral infection includes complex interactions of several mechanisms between the SARS-CoV and test Vero E6 cells, ${ }^{13}$ we then evaluated the effect of phytocompounds specifically on viral replication, by quantification of the amount of spike proteins present in cultures of SARS-CoV infected Vero E6 cells $\left(\mathrm{EC}_{50}\right)$. In addition, a MTT assay was used to determine the $\mathrm{CC}_{50}$ of the test compounds to eliminate any possible cytotoxic or anti-cell proliferation effect of the phytocompounds on the host cells as a cause of a low observed $\mathrm{EC}_{50}$. Once these values were established, the SI (selective index) value was calculated from the ratio of $\mathrm{CC}_{50}$ to $\mathrm{EC}_{50}$ as an indicator of the potency of these compounds. In comparison to the positive controls, niclosamide (21) $)^{28,29}$ and valinomycin (22), ${ }^{10}$ most of the compounds with potent activity against CPE also exhibited marked inhibitory effects on SARS-CoV replication. The SI values (Table 2) for ferruginol (1), dehydroabieta-7-one (2), $8 \beta$ hydroxyabieta-9(11),13-dien-12-one) (5), 7 $\beta$-hydroxydeoxycryptojaponol (6), 3 $\beta$,12-diacetoxyabieta-6,8,11,13-tetraene (8), pinusolidic acid (9), forskolin (10), betulonic acid (14), and 


\section{A Inhibition of SARS-CoV replication}

\section{B Cytotoxic assay}
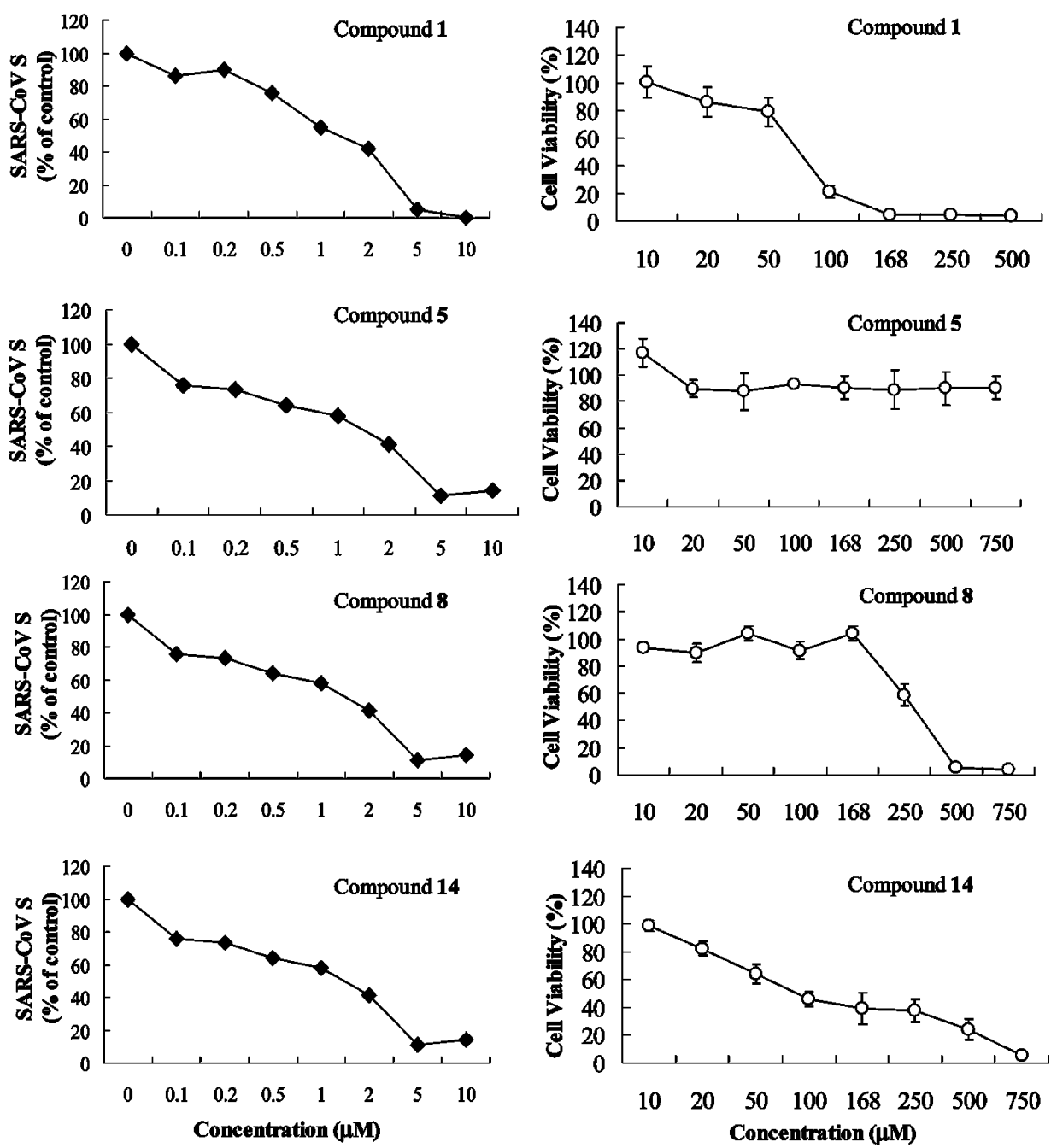

Figure 2. The inhibitory effects of test compounds on replication of SARS-CoV and on proliferation of Vero E6 cells. (A) Inhibition of SARS$\mathrm{CoV}$ replication in response to treatment with specific compounds, as measured by the level of SARS-CoV spike protein (SARS-CoV S) in test Vero E6 cell cultures using ELISA. \% of Control $=\left(\mathrm{OD}_{492}\right.$ of SARS-CoV infection $-\mathrm{OD}_{492}$ of mock infection [concn X])/(OD 492 of SARS-CoV infection - $\mathrm{OD}_{492}$ of Mock infection [concn 0]). (B) Anti-cell proliferation or cytotoxic effects of test compounds on Vero E6 cells determined using MTT assay. Each data point represents the mean $\pm \mathrm{SD}(n=3)$. Cell viability $(\%)=\left(\mathrm{OD}_{570}\right.$ of treated cells $/ \mathrm{OD}_{570}$ of vehicle cells $) \times 100$.

savinin (16) are in fact substantially higher than the SI value of the positive control valinomycin $(\mathbf{2 2})(\mathrm{SI}=41.4)$. These compounds with high SI values apparently inhibit SARS-CoV replication with little or no cytotoxicity against Vero E6 cells and thus have good potential as lead compounds in the future development of anti-SARS drugs. Pinusolidic acid (9) has been reported as a platelet-activating factor inhibitor, ${ }^{30}$ and forskolin (10), a well-known labdane-type diterpene, was reported to activate adenylate cyclase and increase cyclic AMP levels in several cell types. ${ }^{31}$ In this report, we observed potent anti-SARS virus activity for these two compounds.

The SARS-CoV main protease, 3CL protease is involved in the viral maturation process to cleave the virus-encoded polyproteins. Due to its pivotal role in the SARS-CoV life cycle, the 3CL protease is a key target for discovery of anti-SARS$\mathrm{CoV}$ agents. In this report, the inhibitory effects of compounds 1-22 on SARS-CoV 3CL protease activity were investigated. Only betulinic acid $(\mathbf{1 3})\left(K_{\mathrm{i}}=8.2 \pm 0.7 \mu \mathrm{M}\right)$ and savinin (16) $\left(K_{\mathrm{i}}=9.1 \pm 2.4 \mu \mathrm{M}\right)$ exhibited significant inhibition on $3 \mathrm{CL}$ protease. On the basis of structural modeling results (Figure 4), the competitive inhibition of betulinic acid and savinin on 3CL protease activity was due to the formation of multiple hydrogen bonding between the compound and specific amino acid residues located at the active site pocket of the enzyme. So far, a number of efforts have contributed to the identification of inhibitors of SARS-CoV 3CL protease. ${ }^{24,32}$ However, this is the first report to demonstrate that natural lupane-type triterpenes (13) and a lignan (16) block 3CL protease activity by competitive inhibition.

The anti-SARS activity of these two compounds could be the result of a combination of two antiviral mechanisms. One of these is protease inhibition, as demonstrated in the present study. Additionally, evidence from several reports ${ }^{33-36}$ has demonstrated that in the low micromolar range betulinic acid derivatives could effectively interfere with HIV-1 virus entry in test cells at a postbonding, envelope-dependent step apparently related with the fusion of the incoming virus to the host cell membrane. Because of the similarity between the gp41 of the retrovirus HIV-1 and the S2 subunit of the spike protein of SARS-CoV, both of which are responsible for virus-induced membrane fusion, we speculate that a further anti-SARS-CoV mechanism might be the blocking of SARS-CoV entry at the postbinding step during the fusion of virus particle to host cell 
Table 2. Inhibition of Vero E6 Cell Proliferation and SARS-CoV Replication

\begin{tabular}{|c|c|c|c|}
\hline compound & $\mathrm{CC}_{50}(\mu \mathrm{M})^{a}$ & $\mathrm{EC}_{50}(\mu \mathrm{M})^{b}$ & selective index \\
\hline \multicolumn{4}{|c|}{ Diterpenoids (Abietane-type) } \\
\hline 1 & 80.4 & 1.39 & 58.0 \\
\hline 2 & 305.1 & 4.00 & 76.3 \\
\hline 3 & N.T. ${ }^{d}$ & N.T. ${ }^{d}$ & N.C. ${ }^{e}$ \\
\hline 4 & 78.5 & $>10$ & $<7.9$ \\
\hline 5 & $>750$ & 1.47 & $>510$ \\
\hline 6 & 127 & 1.15 & 111 \\
\hline 7 & 89.7 & 5.55 & 16.2 \\
\hline 8 & 303.3 & 1.57 & 193 \\
\hline \multicolumn{4}{|c|}{ Diterpenoids (Labdane-type) } \\
\hline 9 & $>750$ & 4.71 & $>159$ \\
\hline 10 & 674 & 7.5 & 89.8 \\
\hline \multicolumn{4}{|c|}{ Sesquiterpenoids } \\
\hline 11 & $>750$ & $>10$ & N.C. ${ }^{e}$ \\
\hline 12 & 76.8 & 4.44 & 17.3 \\
\hline \multicolumn{4}{|c|}{ Triterpenoids (Lupane-type) } \\
\hline 13 & 150 & $>10$ & $<15$ \\
\hline 14 & 112 & 0.63 & 180 \\
\hline \multicolumn{4}{|c|}{ Lignoids } \\
\hline 15 & $>750$ & $>10$ & N.C. ${ }^{e}$ \\
\hline 16 & $>750$ & 1.13 & $>667$ \\
\hline 17 & N.T. ${ }^{d}$ & N.T. ${ }^{d}$ & N.C. ${ }^{e}$ \\
\hline 18 & 88.9 & 6.50 & 13.7 \\
\hline 19 & 68.3 & 3.80 & 18.0 \\
\hline curcumin, 20 & $>250$ & $>10$ & N.C. ${ }^{e}$ \\
\hline niclosamide, $\mathbf{2 1}$ & 22.1 & $<0.1$ & $>221$ \\
\hline valinomycin, 22 & 67.5 & 1.63 & 41.4 \\
\hline
\end{tabular}

${ }^{a}$ Cytotoxic concentration $\left(\mathrm{CC}_{50}\right)$ of test compounds that reduced cell viability to $50 \%$ of the untreated (control) cell cultures. Each value was calculated from triplicate samples. ${ }^{b}$ Effective concentration $\left(\mathrm{EC}_{50}\right)$ for the inhibition of viral replication to $50 \%$ of the untreated (control) cell cultures. Each value was calculated from triplicate samples. ${ }^{c}$ Selective index was the ratio of $\mathrm{CC}_{50}$ to $\mathrm{EC}_{50}\left(\mathrm{CC}_{50} / \mathrm{EC}_{50}\right) .{ }^{d}$ N.T.: not tested. ${ }^{e}$ N.C.: not calculable

Table 3. Kinetic Properties of Specific Compounds That Inhibit the Enzymatic Activity of SARS-CoV 3CL Protease

\begin{tabular}{lrc}
\hline \multicolumn{1}{c}{ compound } & $\mathrm{IC}_{50}(\mu \mathrm{M})$ & \multicolumn{1}{c}{$K_{\mathrm{i}}{ }^{a}$} \\
\hline betulinic acid (13) & 10 & $8.2 \pm 0.7$ \\
betulonic acid (14) & $>100$ & N.T. $^{b}$ \\
hinokinin (15) & $>100$ & N.T. $^{b}$ \\
savinin (16) & 25 & $9.1 \pm 2.4$ \\
curcumin (20) & 40 & N.T. ${ }^{b}$ \\
niclosamide (21) & 40 & N.T. ${ }^{b}$ \\
\hline
\end{tabular}

${ }^{a} K_{\mathrm{i}}$ value was measured using two fixed compound concentrations and varying substrate concentrations containing $50 \mathrm{nM}$ SARS-CoV protease. ${ }^{b}$ N.T.: not tested.

membrane. The other molecular virological mechanisms apparently affected by these compounds certainly warrant future study.

Various studies have also reported that abietane-type diterpenes exhibited various antiviral activities against Herpes simplex virus (HSV), ${ }^{37,38}$ varicella-zoster virus (VZV), cytomegalovirus (CMV),${ }^{39}$ influenza virus,${ }^{40}$ and human immunodeficiency virus-1 (HIV-1). ${ }^{41,42}$ In addition, some abietane-type diterpenes were also found to inhibit HIV-1 protease. ${ }^{41,42} \mathrm{We}$ observed that the specific abietane-type diterpenes $(\mathbf{1}-\mathbf{8})$ possessed potent anti-SARS viral activities, but that these activities apparently did not involve action on 3CL protease because no 3CL protease inhibition was observed (data not shown). The molecular mechanism(s) by which these compounds operate needs to be investigated further.

The activity of lignans against HSV-I, measles virus, HIV1 , and other types of viruses has been studied..$^{43-45}$ The antiviral mechanisms identified include interference with tubulin binding,
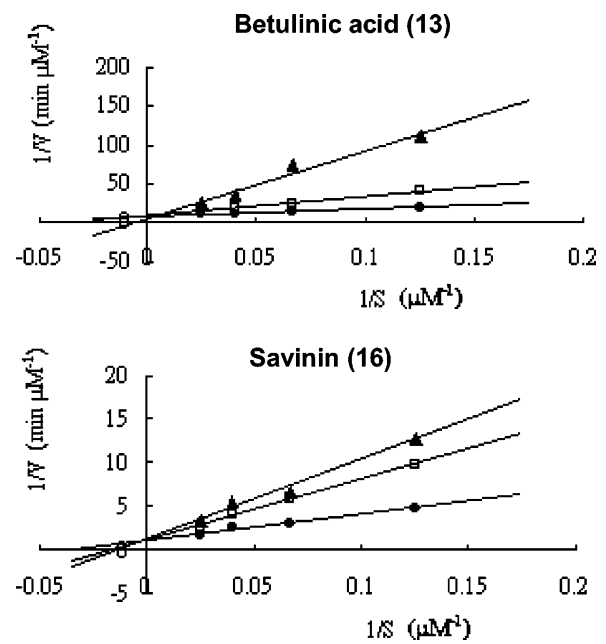

Figure 3. The inhibitory properties of betulinic acid (13) and savinin (16) on the enzymatic activity of SARS-CoV 3CL protease. Protease enzyme activity was measured using $8-80 \mu \mathrm{M}$ of fluorogenic substrate in the absence $(\mathbf{)})$ or presence of $25 \mu \mathrm{M}(\square$ and $50 \mu \mathrm{M}(\mathbf{\Delta})$ compound. The data were fitted with eq 1 using KINETASYST II program to calculate the $K_{\mathrm{i}}$ values of betulinic acid (13) and savinin (16). The inhibition pattern indicates that compounds $\mathbf{1 3}$ and $\mathbf{1 6}$ are competitive inhibitors with respect to the substrate.

inhibition of reverse transcriptase, and inhibition of integrase and topoisomerase activities. ${ }^{43}$ The five lignoids $(\mathbf{1 5}-\mathbf{1 9})$ studied here possessed marked anti-SARS-CoV activity. Among them, savnin (16) $\left(\mathrm{IC}_{50}=25 \mu \mathrm{M}, K_{\mathrm{i}}=9.1 \pm 2.4 \mu \mathrm{M}\right)$ also showed much greater specific protease inhibition than the other lignans tested. This may correlate with its better anti-SARS-CoV proliferation activity in the ELISA test than other compounds (Table 2). Curcumin (20), a known phytocompound from Curcuma longa, has been reported to exhibit antiinflammatory, antioxidant, anticarcinogenic, and anti-HIV activities. ${ }^{46}$ In this study, mild activity against SARS-CoV replication and inhibition of 3CL protease were observed.

Regarding the delivery strategy for the identified bioactive phytocompounds in this study that can or may result in an appropriate bioavailability for the specific type of compounds against SARS virus, we proposed here that diterpene compounds 1-10 can be considered for oral or intravenous (i.v.) administration in future clinical practice. Although we have not found research that directly addresses the bioavailability of diterpenes with the structural features identical to compounds $\mathbf{1 - 1 0}$ in animals or humans, a previous pharmacokinetics study of a diterpene triptolide in male Sprague-Dowley rats after oral and i.v. administration showed that a high oral absolute bioavailability $(72.08 \%)$ was observed at the dose of $0.6 \mathrm{mg} / \mathrm{kg} .{ }^{47}$ Previous pharmacokinetics and plasma and tissue distribution study results of butulinic acid (13) in mice, rat, or dog suggested that intraperitoneal (i.p.) or dermal administration was efficacious for the compound with no observed toxic response in test animals at the dose of $500 \mathrm{mg} / \mathrm{kg}$ body weight. ${ }^{48}$ However, low oral bioavailability $(0.7 \%)$ for oleanolic acid, an analogue of butulinic acid, was observed, implying poor absorption and extensive metabolite clearance. ${ }^{49}$ These results indicate that butulinic acid can be used i.p. or dermal administration without a major problem. On the other hand, the oral or i.v. route for lignoid compounds $\mathbf{1 5 - 1 8}$ administration can be considered as novel because previous studies showed that retrojusticidin B, an analogue of 15-17, suspended in corn oil was observed with a good oral bioavailability $(33.1 \%)$ in rats, ${ }^{50}$ and i.v. administration of honokiol (18) exhibited linear pharmacokinetics in rats. ${ }^{51}$ Specific enteric-coated or tablet-coated formulations may be 
A<smiles>C=C(C)C1CCC2(O)CCC34CCC5C(CCC(O)C5(C)C)C3CCC4C12C</smiles>

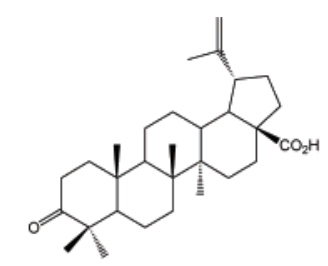
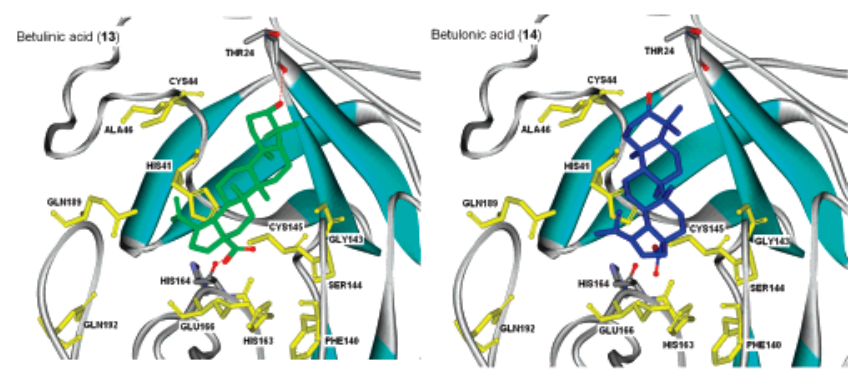

B
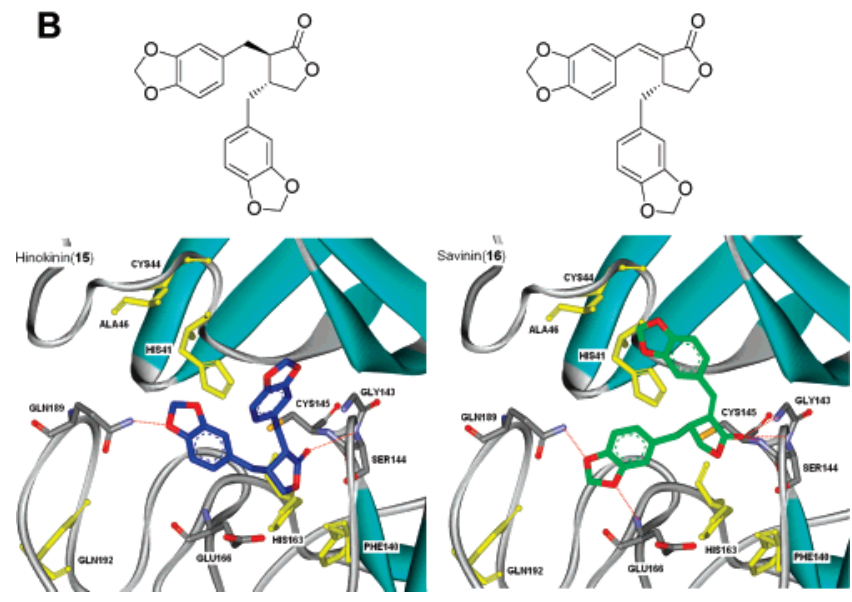

Figure 4. Structural modeling of the binding of compounds 13-16 to SARS-CoV 3CL protease. (A) Ribbon plots of compounds 13 or 14 complexed to SARS-CoV 3CL protease, respectively. (B) Ribbon plots of compounds $\mathbf{1 5}$ or $\mathbf{1 6}$ complexed to SARS-CoV 3CL protease, respectively. The figures depict the predicted intermolecular interactions of compounds in binding to the SARS-CoV 3CL protease. The oxygen atoms in the compounds are indicated in red, and hydrogen bonds are shown as dotted lines.

employed in future clinical or pharmacokinetics studies to enhance the efficacy of oral delivery of specific compounds. Alternatively, nasal spray or oral mucosal delivery may also take advantage of the new approaches in new drug formulation materials that offer improved drug stability and/or bioavailability, and the use of nanoparticles or slow-release delivery strategies.

In conclusion, 20 phytocompounds, including the abietanetype and labdane-type diterpenes, lupane-type triterpenes, liganoids and curcumin, were selected from 221 compounds to undergo a more detailed characterization of their anti-SARS$\mathrm{CoV}$ activity. These phytocompounds were shown for the first time to exhibit significant and specific anti-SARS CoV activity and thus provide a new direction for development of anti-SARS$\mathrm{CoV}$ agents.

Acknowledgment. We thank Dr. Harry Wilson and Ms Miranda Loney, Academia Sinica, for their careful reading of the manuscript.

\section{References}

(1) Ksiazek, T. G.; Erdman, D.; Goldsmith, C. S.; Zaki, S. R.; Peret, T.; Emery, S.; Tong, S.; Urbani, C.; Comer, J. A.; Lim, W.; Rollin, P. E.; Dowell, S. F.; Ling, A. E.; Humphrey, C. D.; Shieh, W. J.;
Guarner, J.; Paddock, C. D.; Rota, P.; Fields, B.; DeRisi, J.; Yang, J. Y.; Cox, N.; Hughes, J. M.; LeDuc, J. W.; Bellini, W. J.; Anderson, L. J. A novel coronavirus associated with severe acute respiratory syndrome. N. Engl. J. Med. 2003, 348, 1953-1966.

(2) Kuiken, T.; Fouchier, R. A.; Schutten, M.; Rimmelzwaan, G. F.; van Amerongen, G.; van Riel, D.; Laman, J. D.; de Jong, T.; van Doornum, G.; Lim, W.; Ling, A. E.; Chan, P. K.; Tam, J. S.; Zambon, M. C.; Gopal, R.; Drosten, C.; van der Werf, S.; Escriou, N.; Manuguerra, J. C.; Stohr, K.; Peiris, J. S.; Osterhaus, A. D. Newly discovered coronavirus as the primary cause of severe acute respiratory syndrome. Lancet 2003, 362, 263-270.

(3) Drosten, C.; Gunther, S.; Preiser, W.; van der Werf, S.; Brodt, H. R.; Becker, S.; Rabenau, H.; Panning, M.; Kolesnikova, L.; Fouchier R. A.; Berger, A.; Burguiere, A. M.; Cinatl, J.; Eickmann, M.; Escriou, N.; Grywna, K.; Kramme, S.; Manuguerra, J. C.; Muller, S.; Rickerts, V.; Sturmer, M.; Vieth, S.; Klenk, H. D.; Osterhaus, A. D.; Schmitz, H.; Doerr, H. W. Identification of a novel coronavirus in patients with severe acute respiratory syndrome. N. Engl. J. Med. 2003, 348, 1967-1976.

(4) Peiris, J. S.; Yuen, K. Y.; Osterhaus, A. D.; Stohr, K. The severe acute respiratory syndrome. N. Engl. J. Med. 2003, 349, 2431-2441.

(5) So, L. K.; Lau, A. C.; Yam, L. Y.; Cheung, T. M.; Poon, E.; Yung, R. W.; Yuen, K. Y. Development of a standard treatment protocol for severe acute respiratory syndrome. Lancet 2003, 361, 16151617.

(6) Cinatl, J.; Morgenstern, B.; Bauer, G.; Chandra, P.; Rabenau, H.; Doerr, H. W. Glycyrrhizin, an active component of liquorice roots, and replication of SARS-associated coronavirus. Lancet 2003, 361, 2045-2046.

(7) Stroher, U.; DiCaro, A.; Li, Y.; Strong, J. E.; Aoki, F.; Plummer, F.; Jones, S. M.; Feldmann, H. Severe acute respiratory syndrome-related coronavirus is inhibited by interferon- alpha. J. Infect. Dis. 2004, 189, 1164-1167.

(8) Chan, K. S.; Lai, S. T.; Chu, C. M.; Tsui, E.; Tam, C. Y.; Wong, M. M.; Tse, M. W.; Que, T. L.; Peiris, J. S.; Sung, J.; Wong, V. C.; Yuen, K. Y. Treatment of severe acute respiratory syndrome with lopinavir/ritonavir: a multicentre retrospective matched cohort study. Hong Kong Med. J. 2003, 9, 399-406.

(9) Chu, C. M.; Poon, L. L.; Cheng, V. C.; Chan, K. S.; Hung, I. F.; Wong, M. M.; Chan, K. H.; Leung, W. S.; Tang, B. S.; Chan, V. L.; Ng, W. L.; Sim, T. C.; Ng, P. W.; Law, K. I.; Tse, D. M.; Peiris, J. S.; Yuen, K. Y. Initial viral load and the outcomes of SARS. Can. Med. Assoc. J. 2004, 171, 1349-1252.

(10) Wu, C. Y.; Jan, J. T.; Ma, S. H.; Kuo, C. J.; Juan, H. F.; Cheng, Y. S.; Hsu, H. H.; Huang, H. C.; Wu, D.; Brik, A.; Liang, F. S.; Liu, R. S.; Fang, J. M.; Chen, S. T.; Liang, P. H.; Wong, C. H. Small molecules targeting severe acute respiratory syndrome human coronavirus. Proc. Natl. Acad. Sci. U.S.A. 2004, 101, 10012-10017.

(11) Hoever, G.; Baltina, L.; Michaelis, M.; Kondratenko, R.; Baltina, L.; Tolstikov, G. A.; Doerr, H. W.; Cinatl, J., Jr. Antiviral activity of glycyrrhizic acid derivatives against SARS-coronavirus. J. Med. Chem. 2005, 48, 1256-1259.

(12) Barnard, D. L.; Hubbard, V. D.; Burton, J.; Smee, D. F.; Morrey, J. D.; Otto, M. J.; Sidwell, R. W. Inhibition of severe acute respiratory syndrome-associated coronavirus (SARSCoV) by calpain inhibitors and beta-D-N4-hydroxycytidine. Antivir. Chem. Chemother. 2004 $15,15-22$

(13) Stadler, K.; Masignani, V.; Eickmann, M.; Becker, S.; Abrignani, S.; Klenk, H. D.; Rappuoli, R. SARS-beginning to understand a new virus. Nat. Rev. Microbiol. 2003, 1, 209-218.

(14) Lai, S. T. Treatment of severe acute respiratory syndrome. Eur. J. Clin. Microbiol. Infect. Dis. 2005, 24, 583-91.

(15) Groneberg, D. A.; Poutanen, S. M.; Low, D. E.; Lode, H.; Welte, T.; Zabel, P. Treatment and vaccines for severe acute respiratory syndrome. Lancet Infect. Dis. 2005, 5, 147-155.

(16) Kliger, Y.; Levanon, E. Y.; Gerber, D. From genome to antivirals: SARS as a test tube. Drug. Discovery Today. 2005, 10, 345-352.

(17) De Clercq, E. Antivirals and antiviral strategies. Nat. Rev. Microbiol. 2004, 2, 704-720.

(18) Holmes, K. V. SARS coronavirus: a new challenge for prevention and therapy. J. Clin. Invest. 2003, 111, 1605-1609.

(19) Gallagher, T. M.; Buchmeier, M. Coronavirus spike proteins in viral entry and pathogenesis. J. Virology. 2001, 279, 371-374.

(20) Tan, E. L.; Ooi, E. E.; Lin, C. Y.; Tan, H. C.; Ling, A. E.; Lim, B.; Stanton, L. W. The crystal structures of severe acute respiratory syndrome virus main protease and its complex with an inhibitor. Emerg. Infect. Dis. 2004, 10, 581-586.

(21) Kuo, C. J.; Chi, Y. H.; Hsu, J. T.; Liang, P. H. Characterization of SARS main protease and inhibitor assay using a fluorogenic substrate. Biochem. Biophys. Res. Commun. 2004, 318, 862-867. 
(22) Yang, H.; Yang, M.; Ding, Y.; Liu, Y.; Lou, Z.; Zhou, Z.; Sun, L.; Mo, L.; Ye, S.; Pang, H.; Gao, G. F.; Anand, K.; Bartlam, M.; Hilgenfeld, R.; Rao, Z. Probing the conformational change of Escherichia coli undecaprenyl pyrophosphate synthase during catalysis using an inhibitor and tryptophan mutants. Proc. Natl. Acad. Sci. U.S.A. 2003, 100, 13190-13195.

(23) Chen, Y. H.; Chen, A. P.; Chen, C. T.; Wang, A. H.; Liang, P. H The crystal structures of severe acute respiratory syndrome virus main protease and its complex with an inhibitor. J. Biol. Chem. 2002, 277, 7369-7376.

(24) Shie, J. J.; Fang, J. M.; Kuo, C. J.; Kuo, T. H.; Liang, P. H.; Huang, H. J.; Yang, W. B.; Lin, C. H.; Chen, J. L.; Wu, Y. T.; Wong, C. H. Discovery of potent anilide inhibitors against the severe acute respiratory syndrome 3CL protease. J. Med. Chem. 2005, 48, 44697443.

(25) Cheng, S. S.; Wu, C. L.; Chang, H. T.; Kao, Y. T.; Chang, S. T. Antitermitic and antifungal activities of essential oil of Calocedrus formosana leaf and its composition. J. Chem. Ecol. 2004, 30, 19571967.

(26) Chang, S. T.; Cheng, S. S.; Wang, S. Y. Antitermitic activity of essential oils and components from Taiwania (Taiwania cryptomerioides). J. Chem. Ecol. 2001, 27, 717-724.

(27) He, K.; Zeng, L.; Shi, G.; Zhao, G. X.; Kozlowski, J. F.; McLaughlin, J. L. Bioactive compounds from Taiwania cryptomerioides. J. Nat. Prod. 1997, 60, 38-40.

(28) Zhang, X. W.; Yap, Y. L. Old drugs as lead compounds for a new disease? Binding analysis of SARS coronavirus main proteinase with HIV, psychotic and parasite drugs. Bioorg. Med. Chem. 2004, 12, 2517-2521.

(29) Wu, C. J.; Jan, J. T.; Chen, C. M.; Hsieh, H. P.; Hwang, D. R.; Liu, H. W.; Liu, C. Y.; Huang, H. W.; Chen, S. C.; Hong, C. F.; Lin, R. K.; Chao, Y. S.; Hsu, J. T. Inhibition of severe acute respiratory syndrome coronavirus replication by niclosamide. Antimicrob. Agents. Chemother. 2004, 48, 2693-2696.

(30) Yang, H. O.; Han, B. H. Pinusolidic acid: a platelet-activating factor inhibitor from Biota orientalis. Planta Med. 1998, 64, 72-74.

(31) Insel, P. A.; Ostrom, R. S. Forskolin as a tool for examining adenylyl cyclase expression, regulation, and $\mathrm{G}$ protein signaling. Cell $\mathrm{Mol}$. Neurobiol. 2003, 23, 305-314.

(32) Liang, P. H. Characterization and inhibition of SARS-coronavirus main protease. Curr. Top Med. Chem. 2006, 6, 361-376.

(33) Mayaux, J. F.; Bousseau, A.; Pauwels, R.; Huet, T.; Henin, Y.; Dereu, N.; Evers, M.; Soler, F.; Poujade, C.; De Clercq, E.; et al. Triterpene derivatives that block entry of human immunodeficiency virus type 1 into cells. Proc. Natl. Acad. Sci. U.S.A 1994, 91, 3564-3568.

(34) Reissman, P. Significance of anal canal ultrasound before sphincterotomy in multiparous women with anal fissure. Dis. Colon Rectum 1996, 39, 1060

(35) Soler, F.; Poujade, C.; Evers, M.; Carry, J. C.; Henin, Y.; Bousseau, A.; Huet, T.; Pauwels, R.; De Clercq, E.; Mayaux, J. F.; Le Pecq, J. B.; Dereu, N. Betulinic acid derivatives: a new class of specific inhibitors of human immunodeficiency virus type 1 entry. J. Med. Chem. 1996, 39, 1069-1083.

(36) Ito, J.; Chang, F. R.; Wang, H. K.; Park, Y. K.; Ikegaki, M.; Kilgore, N.; Lee, K. H. Anti-AIDS agents. 48. Anti-HIV activity of moronic acid derivatives and the new melliferone-related triterpenoid isolated from Brazilian propolis. J. Nat. Prod. 2001, 64, 1278-1281.
(37) Batista, O.; Simoes, M. F.; Duarte, A.; Valdeira, M. L.; de la Torre, M. C.; Rodriguez, B. An antimicrobial abietane from the root of Plectranthus hereroensis. Phytochemistry 1995, 38, 167-169.

(38) Gigante, B.; Santos, C.; Silva, A. M.; Curto, M. J.; Nascimento, M. S.; Pinto, E.; Pedro, M.; Cerqueira, F.; Pinto, M. M.; Duarte, M. P.; Laires, A.; Rueff, J.; Goncalves, J.; Pegado, M. I.; Valdeira, M. L. Catechols from abietic acid synthesis and evaluation as bioactive compounds. Bioorg. Med. Chem. 2003, 11, 1631-1638.

(39) Fonseca, T.; Gigante, B.; Marques, M. M.; Gilchrist, T. L.; De Clercq, E. Synthesis and antiviral evaluation of benzimidazoles, quinoxalines and indoles from dehydroabietic acid. Bioorg. Med. Chem. 2004, $12,103-112$.

(40) Staschke, K. A.; Hatch, S. D.; Tang, J. C.; Hornback, W. J.; Munroe, J. E.; Colacino, J. M.; Muesing, M. A. Inhibition of influenza virus hemagglutinin-mediated membrane fusion by a compound related to podocarpic acid. Virology 1998, 248, 264-274.

(41) Paris, A.; Strukelj, B.; Renko, M.; Turk, V.; Pukl, M.; Umek, A.; Korant, B. D. Inhibitory effect of carnosic acid on HIV-1 protease in cell-free assays. J. Nat. Prod. 1993, 56, 1426-1430.

(42) Aruoma, O. I.; Spencer, J. P.; Rossi, R.; Aeschbach, R.; Khan, A.; Mahmood, N.; Munoz, A.; Murcia, A.; Butler, J.; Halliwell, B. An evaluation of the antioxidant and antiviral action of extracts of rosemary and Provencal herbs. Food Chem. Toxicol. 1996, 34, 449456.

(43) Charlton, J. L. Antiviral activity of lignans. J. Nat. Prod. 1998, 61, 1447-1451.

(44) Eich, E.; Pertz, H.; Kaloga, M.; Schulz, J.; Fesen, M. R.; Mazumder, A.; Pommier, Y. (-)-Arctigenin as a lead structure for inhibitors of human immunodeficiency virus type-1 integrase. J. Med. Chem. 1996, 39, 86-95

(45) Hara, H.; Fujihashi, T.; Sakata, T.; Kaji, A.; Kaji, H. Tetrahydronaphthalene lignan compounds as potent anti-HIV type 1 agents. AIDS Res. Hum. Retroviruses 1997, 13, 695-705.

(46) Joe, B.; Vijaykumar, M.; Lokesh, B. R. Biological properties of curcumin-cellular and molecular mechanisms of action. Crit. Rev Food. Sci. Nutr. 2004, 44, 97-111.

(47) Shao, F.; Wang, G.; Xie, H.; Zhu, X.; Sun, J.; A, J. Pharmacokinetics study of triptolide, a constituent of immunosuppressive Chinese herb medicine, in rats. Biol. Pharm. Bull. 2007, 30, 702-707.

(48) Cheng, X.; Shin, Y. G.; Levine, B. S.; Smith, A. C.; Tomaszewski, J. E.; van Breemen, R. B. Quantitative analysis of betulinic acid in mouse, rat and dog plasma using electrospray liquid chromatography/ mass spectrometry. Rapid Commun. Mass Spectrom. 2003, 17, 20892092

(49) Jeong, D. W.; Kim, Y. H.; Kim, H. H.; Ji, H. Y.; Yoo, S. D.; Choi, W. R.; Lee, S. M.; Han, C.-K.; Lee, H. S. Dose-linear pharmacokinetics of oleanolic acid after intravenous and oral administration in rats. Biopharm. Drug Dispos. 2007, 28, 51-57.

(50) Wang, C.-Y.; Sun, S.-W.; Lee, S.-S. Pharmacokinetic and metabolic studies of retrojusticidin $\mathrm{B}$, a potential anti-viral lignan, in rats. Planta Med. 2004, 70, 1161-1165.

(51) Tsai, T.-H.; Chou, C.-J.; Cheng, F.-C.; Chen, C.-F. Pharmacokinetics of honokiol after intravenous administration in rats assessed using high-performance liquid chromatography. J. Chromatogr. B 1994, $655,41-45$.

JM070295S 